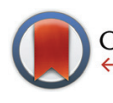

CrossMark \&lick for updates

Cite this: Dalton Trans., 2014, 43 15812

Received 9th July 2014,

Accepted 26th August 2014

DOI: $10.1039 / c 4 d t 02084 \mathrm{~g}$

www.rsc.org/dalton

\title{
Synthesis and crystal structure of a series of incommensurately modulated composite oxohalide compounds $\uparrow$
}

\author{
Iwan Zimmermann, ${ }^{a}$ Alexis Corgnet, ${ }^{a}$ Mats Johnsson ${ }^{\star a}$ and Sven Lidin ${ }^{\mathrm{b}}$ \\ Transparent, needle-like single crystals of the isostructural compounds $\left[\mathrm{Sb}_{4} \mathrm{O}_{7+3 \delta} \mathrm{X}_{4}\right]\left[\mathrm{Zn}_{3}\right]_{1+\delta}(\mathrm{X}=\mathrm{Cl}, \mathrm{Br}, \mathrm{I})$ \\ $\delta \approx 0.2$ were obtained from chemical reactions in evacuated and sealed silica tubes. First, the average \\ structure was solved in $P 2_{1} / n$ but the model refined poorly and a lowering of the symmetry to the $3+1$ \\ dimensional space group $P 2_{1}(\alpha 0 \gamma) 0$ gave a significantly better fit to the data. This model used second \\ order positional modulations for all the atoms. Whereas $\mathrm{Sb}, \mathrm{Cl}(\mathrm{Br}, \mathrm{I})$ and most $\mathrm{O}$ positions were well \\ behaved, there was a mismatch with $\mathrm{Zn}$ that was better described in a sub-cell, thus yielding a composite \\ structure. The composite nature of the structure leads to a charge imbalance that is compensated by \\ oxygen vacancies.
}

\section{Introduction}

A rich structural variety exists among oxides and oxohalides containing antimony because of the flexibility of the coordination of $\mathrm{Sb}^{3+}$. The stereochemically active lone-pair on $\mathrm{Sb}^{3+}$ causes an asymmetric coordination, and the most common coordination polyhedra are $\left[\mathrm{SbO}_{3}\right]$ trigonal pyramids and $\left[\mathrm{SbO}_{4}\right]$ see-saws.

For ternary $\mathrm{Sb}-\mathrm{O}-\mathrm{X}(\mathrm{X}=\mathrm{Cl}, \mathrm{Br}, \mathrm{I})$ compounds, there is a tendency for the halide ion to take the role of a counter ion rather than forming covalent bonds with antimony. For quaternary compounds also containing a late transition metal, it is most common that antimony only coordinates with oxygen and the transition metal bond to both oxygen and halide ions. This results in the formation of non-bonding volumes in the crystal structure between chalcogen/chalcophile and halogen/ halophile parts, where the terminal halogens and lonepairs become next neighbors. The most reasonable explanation for this behavior is that they are excluded from the bonding subvolume of the structure rather than being attracted to each other. The flexibility in the coordination around $\mathrm{Sb}^{3+}$ and its

\footnotetext{
${ }^{a}$ Department of Materials and Environmental Chemistry, Stockholm University, SE-10691 Stockholm, Sweden. E-mail: mats.johnsson@mmk.su.se; Fax: +46-8-152187; Tel: +46-8-162169

${ }^{b}$ Department of Chemistry, Division of Polymer \& Materials Chemistry, Lund University, Box 124, SE-221 00 Lund, Sweden

$\dagger$ Electronic supplementary information (ESI) available: Further details on crystal structural investigations can be obtained from the Fachinformationszentrum Karlsruhe, Abt. PROKA, 76344 Eggenstein-Leopoldshafen, Germany (fax +497247-808-666; E-mail: crysdata@fiz-karlsruhe.de) on quoting the following depository numbers: CSD 427521 for $\left[\mathrm{Sb}_{4} \mathrm{O}_{7+3 \delta} \mathrm{Cl}_{4}\right]\left[\mathrm{Zn}_{3}\right]_{1+\delta}$, CSD 427522 for $\left[\mathrm{Sb}_{4} \mathrm{O}_{7+3 \delta} \mathrm{Br}_{4}\right]\left[\mathrm{Zn}_{3}\right]_{1+\delta}$, and CSD 427523 for $\left[\mathrm{Sb}_{4} \mathrm{O}_{7+3 \delta} \mathrm{I}_{4}\right]\left[\mathrm{Zn}_{3}\right]_{1+\delta}$. See DOI: $10.1039 /$ c4dt02084g
}

preference to bond only to oxygen led to several types of antimony oxide entities, e.g. small cages resembling cubic $\mathrm{Sb}_{2} \mathrm{O}_{3}$ in $\mathrm{CuSb}_{2} \mathrm{O}_{3} \mathrm{Br},{ }^{1}$ bigger cages resembling zeolite $\beta$-cages in $\mathrm{Cu}_{20} \mathrm{Sb}_{35} \mathrm{O}_{44} \mathrm{Cl}_{37},{ }^{2}$ layers in $\mathrm{CuSbTeO}_{3} \mathrm{Cl}_{2}{ }^{3}$ and tubes in $\mathrm{Sb}_{8} \mathrm{O}_{11} \mathrm{X}_{2} \cdot{ }^{4-6}$ In this work, we present the isostructural compounds $\left[\mathrm{Sb}_{4} \mathrm{O}_{7+3 \delta} \mathrm{X}_{4}\right]\left[\mathrm{Zn}_{3}\right]_{1+\delta}(\mathrm{X}=\mathrm{Cl}, \mathrm{Br}, \mathrm{I}), \delta \approx 0.2$ with a rather simple columnar average structure that actually proved to be a composite structure, in which the $\mathrm{Zn}$ atoms are best described in a sub-cell. Composite structures are relatively rare and are mainly observed among intermetallic compounds and among sulfides and fluorides. ${ }^{7}$ However, the latter are mostly layer misfit compounds, and there is also a good example of columnar misfit: the "alchemist's gold", $\mathrm{Hg}_{2.86} \mathrm{AsF}_{6}{ }^{8,9}$ Oxide-based, modulated composite structures have been found in several hexagonal perovskites and related materials such as e.g. $\mathrm{Sr}_{1.2872} \mathrm{NiO}_{3},{ }^{10} \mathrm{Sr}_{1+x}\left(\mathrm{Co}_{x} \mathrm{Mn}_{1-x}\right) \mathrm{O}_{3},{ }^{11} \quad \mathrm{Ba}_{1+x}\left[\left(\mathrm{Cu}_{x} \mathrm{Rh}_{1-x}\right) \mathrm{O}_{3}\right]^{12}$ and $\mathrm{Sr}_{1+x}\left(\mathrm{Cu}_{x} \mathrm{Mn}_{1-x}\right) \mathrm{O}_{3 .}{ }^{13}$ To the best of our knowledge the present compounds are the first oxohalides to show a composite structure.

\section{Experimental}

Transparent, needle-like single crystals of the compounds $\left[\mathrm{Sb}_{4} \mathrm{O}_{7+3 \delta} \mathrm{Cl}_{4}\right]\left[\mathrm{Zn}_{3}\right]_{1+\delta}, \quad\left[\mathrm{Sb}_{4} \mathrm{O}_{7+3 \delta} \mathrm{Br}_{4}\right]\left[\mathrm{Zn}_{3}\right]_{1+\delta}$ and $\left[\mathrm{Sb}_{4} \mathrm{O}_{7+3 \delta} \mathrm{I}_{4}\right]-$ $\left[\mathrm{Zn}_{3}\right]_{1+\delta}, \delta \approx 0.2$ were obtained from chemical reactions in evacuated and sealed silica tubes. $\mathrm{ZnO}(\mathrm{ABCR}), \mathrm{ZnCl}_{2}$ (SigmaAldrich), $\mathrm{ZnBr}_{2}$ (Sigma-Aldrich), $\mathrm{ZnI}_{2}$ (ABCR) and $\mathrm{Sb}_{2} \mathrm{O}_{3}$ (Sigma-Aldrich) were used as starting materials. For the synthesis, a 1:1:1 mixture of $\mathrm{ZnX}_{2}(\mathrm{X}=\mathrm{Cl}, \mathrm{Br}$, or I $), \mathrm{ZnO}_{2}$ and $\mathrm{Sb}_{2} \mathrm{O}_{3}$ was subsequently heat treated at $550{ }^{\circ} \mathrm{C}$ for $60 \mathrm{~h}$. Single 
Table 1 Crystallographic information for $\left[\mathrm{Sb}_{4} \mathrm{O}_{7+3 \delta} \mathrm{X}_{4}\right]\left[\mathrm{Zn}_{3}\right]_{1+\delta}(\mathrm{X}=\mathrm{Cl}, \mathrm{Br}, \mathrm{I}), \delta \approx 0.2$

\begin{tabular}{|c|c|c|c|}
\hline Compound & {$\left[\mathrm{Sb}_{4} \mathrm{O}_{7+3 \delta} \mathrm{I}_{4}\right]\left[\mathrm{Zn}_{3}\right]_{1+\delta}$} & {$\left[\mathrm{Sb}_{4} \mathrm{O}_{7+3 \delta} \mathrm{Br}_{4}\right]\left[\mathrm{Zn}_{3}\right]_{1+\delta}$} & {$\left[\mathrm{Sb}_{4} \mathrm{O}_{7+3 \delta} \mathrm{Cl}_{4}\right]\left[\mathrm{Zn}_{3}\right]_{1+\delta}$} \\
\hline Space group & $P 2_{1}(\alpha 0 \gamma) 0$ & $P 2_{1}(\alpha 0 \gamma) 0$ & $P 2_{1}(\alpha 0 \gamma) 0$ \\
\hline & $-x 1, x 2+0.5,-x 3,-x 4$ & $-x 1, x 2+0.5,-x 3,-x 4$ & $-x 1, x 2+0.5,-x 3,-x 4$ \\
\hline$c / \AA$ & $10.6741(14)$ & $10.3021(10)$ & $10.4699(13)$ \\
\hline$\beta /{ }^{\circ}$ & $90.054(13)$ & $90.331(6)$ & $91.024(11)$ \\
\hline$q$ & $\left(\begin{array}{c}0.2274(7) \\
0 \\
0.4236(15)\end{array}\right)$ & $\left(\begin{array}{c}0.226(3) \\
0 \\
0.399(6)\end{array}\right)$ & $\left(\begin{array}{c}0.2032(5) \\
0 \\
0.3602(12)\end{array}\right)$ \\
\hline Crystal colour/habit & Colourless/needle & Colourless/needle & Colourless/needle \\
\hline Crystal dimensions & $0.32 \times 0.04 \times 0.03$ & $0.21 \times 0.03 \times 0.02$ & $0.20 \times 0.04 \times 0.02$ \\
\hline No. of reflections all/ $/[>3 \sigma(I)]$ & $16749 / 4073$ & $26084 / 6011$ & $22220 / 3537$ \\
\hline Goodness of fit $S$ & 1.51 & 2.02 & 1.39 \\
\hline$R$ factors $[I>3 \sigma(I)]$ & $R_{1}=0.0729\left(\mathrm{w} R_{2}=0.0711\right)$ & $R_{1}=0.0982\left(\mathrm{w} R_{2}=0.1015\right)$ & $R_{1}=0.0714\left(\mathrm{w} R_{2}=0.0690\right)$ \\
\hline Equivalents & $R_{\mathrm{int}}=0.0701$ & $R_{\mathrm{int}}=0.1192$ & $R_{\mathrm{int}}=0.1486$ \\
\hline
\end{tabular}

crystals were separated manually from unreacted starting material and crystals of the previously described compound $\mathrm{ZnSb}_{2} \mathrm{O}_{4}{ }^{14}$ that was observed in minor amounts as by-product. Attempts to synthesize a corresponding oxofluoride phase starting with $\mathrm{ZnF}_{2}$ as a fluorine source failed.

Single-crystal X-ray diffraction experiments were carried out on an Oxford Diffraction Xcalibur3 diffractometer equipped with a graphite monochromator. The data collection was at $293 \mathrm{~K}$ using MoK $\alpha$ radiation, $\lambda=0.71073 \AA$ A . Data reduction was performed with the software CrysAlis RED, which was also employed for the analytical absorption correction. The crystal structures were solved by charge flipping implemented in SUPERFLIP $^{15}$ and refined by full matrix least squares on $\mathrm{F}$ using the program JANA-2006; ${ }^{16}$ the $\mathrm{W}$ matrix was calculated according to van Smaalen. ${ }^{17,18}$

The structural drawings are made with the program DIAMOND. ${ }^{19}$ Powder patterns were collected on a Panalytical X'Pert PRO powder X-ray diffractometer in Bragg-Brentano geometry with $\mathrm{Cu}-\mathrm{K}_{\alpha}$ radiation. IR spectra were recorded on a Varian 670-IR FTIR spectrometer in the range $390-4000 \mathrm{~cm}^{-1}$ at ambient temperature. The spectrometer was equipped with an attenuated total reflection (ATR) detection device with a single reflection ATR diamond element. Thermogravimetric studies were performed in a Perkin-Elmer TGA7 unit in nitrogen with a heating rate of $5{ }^{\circ} \mathrm{C} \mathrm{min}^{-1}$.

\section{Results}

An inspection of reciprocal space images from compounds $\left[\mathrm{Sb}_{4} \mathrm{O}_{7+3 \delta} \mathrm{X}_{4}\right]\left[\mathrm{Zn}_{3}\right]_{1+\delta}(\mathrm{X}=\mathrm{Cl}, \mathrm{Br}, \mathrm{I}), \delta \approx 0.2$ clearly show that the structures are incommensurately modulated with a $\boldsymbol{q}$ vector in the ac-plane of the fundamental monoclinic unit cell. The close-to-perfect orthorhombic pseudo-symmetry of the fundamental unit cell and the presence of two (orthorhombically) symmetry-equivalent $\boldsymbol{q}$-vectors clearly indicates that pseudo- merohedral twinning according to the orthorhombic-monoclinic symmetry lowering is expected. All the structures contain a set of strong substructure reflections and a set of weaker satellites that appear to be incommensurate with the substructure.

The crystallographic information of the three compounds is summarized in Table 1. The value of $\delta$ is given by the $\boldsymbol{q}$ vector component along $a^{*}$. The patterns further share the special feature that first-order satellites dominate for the $1 \mathrm{kl}$ reflections,

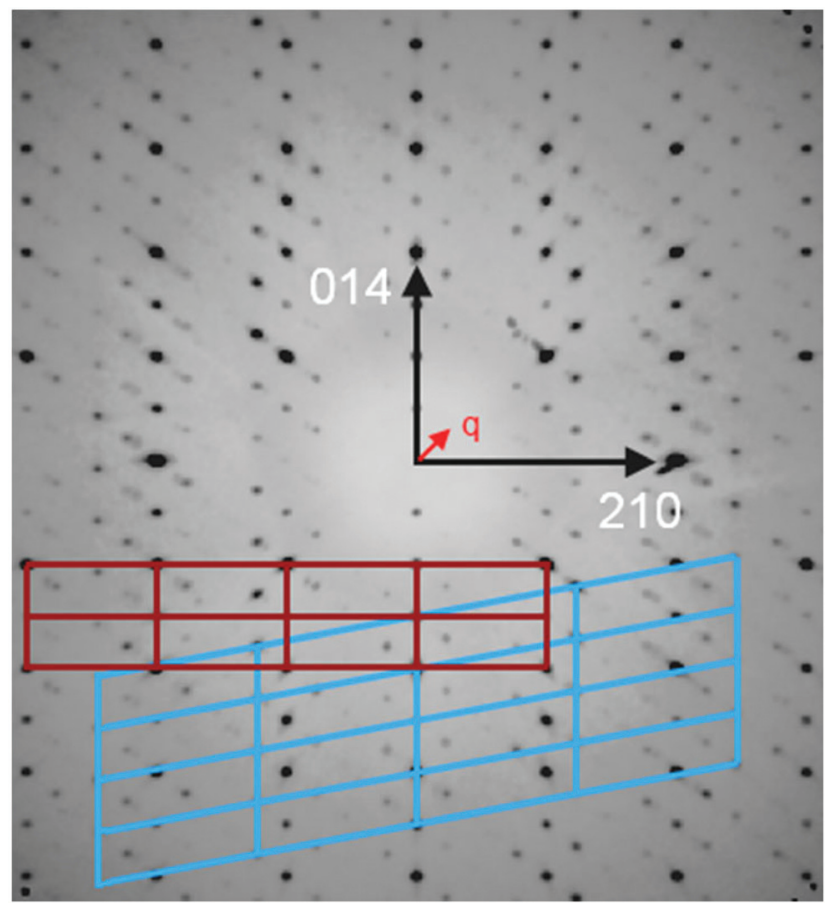

Fig. 1 Reconstructed reciprocal lattice section $h k l$ integrated from $k=$ 0 to $k=4$ of the iodide compound. Note the relative intensity of firstorder satellites for $1 k l$ reflections and second-order satellites for $2 k l$ reflections. Primary and secondary unit cells are indicated in red and blue, respectively. 

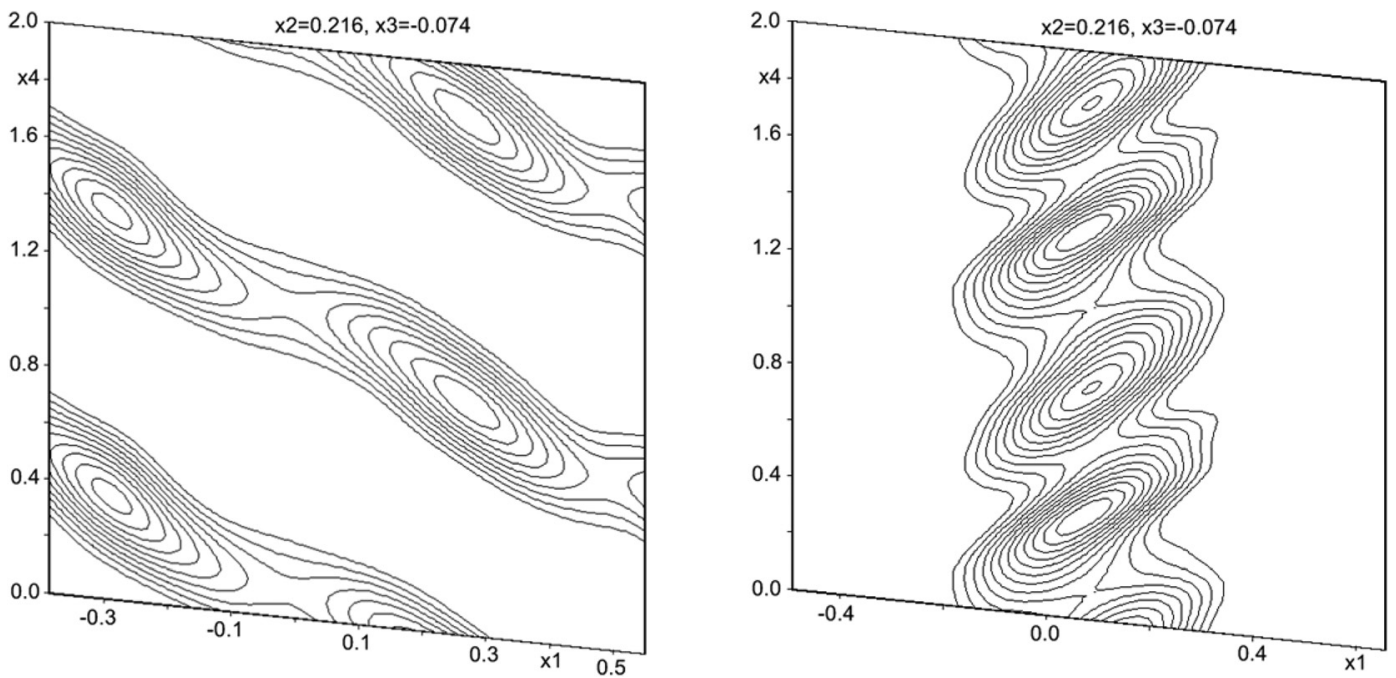

Fig. 2 Electron density map of Zn1 in the primary (left) and the secondary unit cells (right).

and the second-order satellites dominate for the $2 k l$ reflections, as shown in Fig. 1. This is a strong indication for composite behavior.

Structural solutions using charge flipping in superspace (superflip) of the compounds was relatively straight-forward. A first structural solution was carried out in the centro-symmetric space group $P 2_{1} / n$ but this solution refined rather poorly. Lowering the symmetry to $P n$ did little to improve the situation, whereas a model in the $3+1$ dimensional space group $P 2_{1}(\alpha 0 \gamma) 0$ provided a considerably better fit to the data. This model used second-order positional modulations for all the atoms. The automatic procedure produced excellent starting positions and modulations for $\mathrm{Sb}$ and halides, whereas the modulations for $\mathrm{Zn}$ turned out to be very large. Oxygen positions were only localized to some extent. The amplitude of the

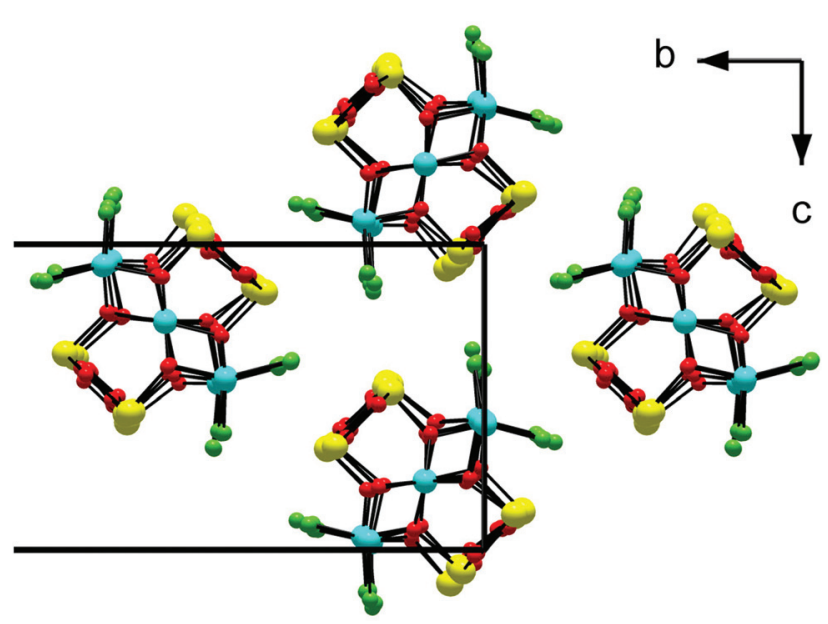

Fig. 3 Structure of single columns of $\mathrm{SbZn}_{1-y} \mathrm{O}_{2-y} \mid$ viewed along a. Zinc (blue) is coordinated entirely by oxygen (red) or by oxygen and iodine (green), whereas antimony forms oxygen-connected ladders. Note the exposure of $\mathrm{Sb}$ to the surroundings of the column, a typical trait of lone-pair behavior. modulation of $\mathrm{Zn}$ positions was particularly large along the $a$ direction, and while this could be modeled as a saw-tooth type positional modulation, it was clear that a composite structure model would be more suitable (see Fig. 2). After moving all the Zn positions to the secondary unit cell using the transformation matrix expressed as

$$
W_{2}=\left(\begin{array}{llll}
1 & 0 & 0 & 1 \\
0 & 1 & 0 & 0 \\
0 & 0 & 1 & 0 \\
0 & 0 & 0 & 1
\end{array}\right)
$$

refining the structure as pseudo-merohedrally twinned proceeded without further complications. All oxygen positions were located and in the final model found to be best described in the primary unit cell.

The compounds $\left[\mathrm{Sb}_{4} \mathrm{O}_{7+3 \delta} \mathrm{X}_{4}\right]\left[\mathrm{Zn}_{3}\right]_{1+\delta},(\mathrm{X}=\mathrm{Cl}, \mathrm{Br}, \mathrm{I}), \delta \approx 0.2$ are isostructural, and may be described by the behavior of the iodide compound without loss of generality. The Br compound produced crystals of relatively low quality, and for these convergence was difficult to achieve. The problem was solved by restricting all oxygen thermal displacement parameters to be equal. The non-stoichiometry originates from the composite nature of the structures. The primary unit cell is the locus of

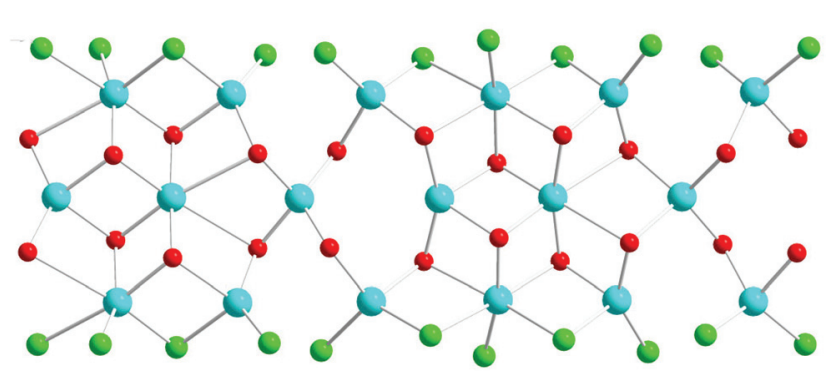

Fig. 4 Coeur-du-filé of a single column of the structure, displaying the misfit between on one hand $\mathrm{Zn}$ (blue) and on the other hand oxygen (red) and I (green). The a direction is horizontal. 

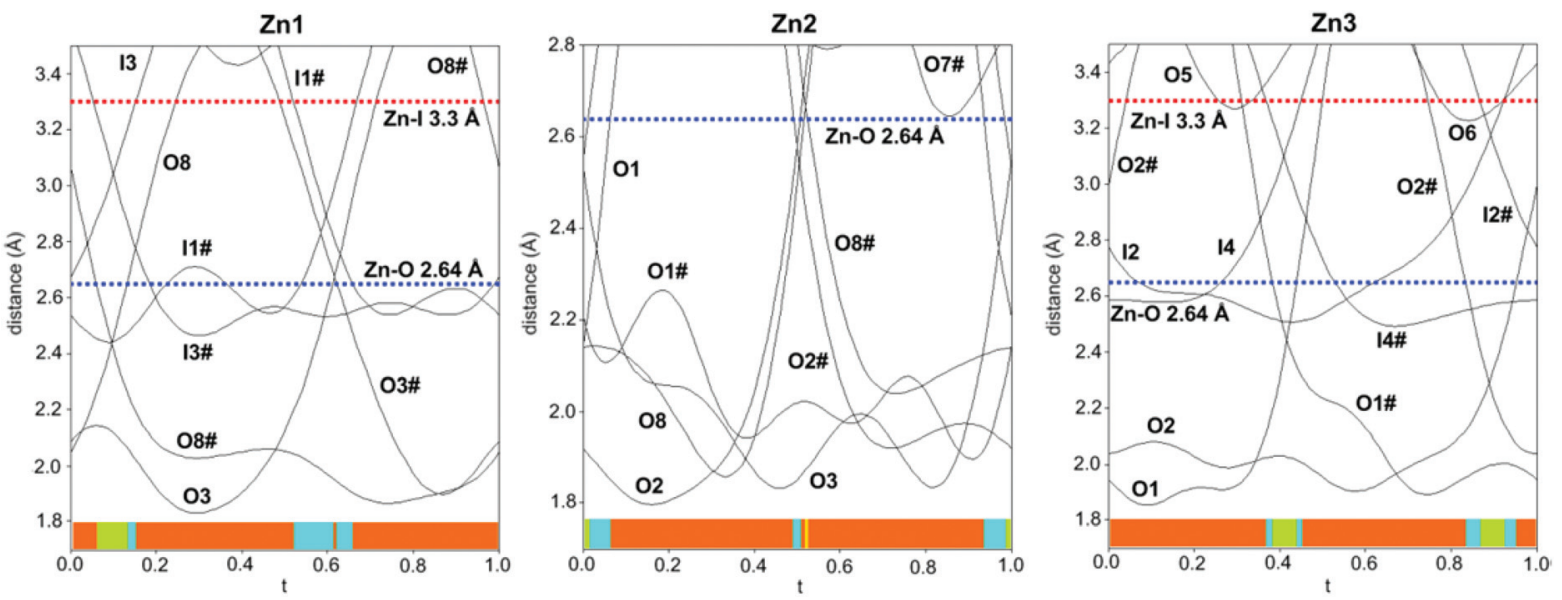

Fig. 5 Variation in the coordination around the three crystallographically different $\mathrm{Zn}$-atoms in the form of $t$-plots. The maximum $\mathrm{Zn}-\mathrm{O}$ and $\mathrm{Zn}-\mathrm{I}$ distances to be considered for covalent bonding are indicated with dotted lines. The coordination number is outlined with colored bars; yellow = 3 -coordination, red $=4$-coordination, blue $=5$-coordination, and green $=6$-coordination. $\#$ sign implies symmetry-equivalent atoms.

the $\mathrm{Sb}_{4} \mathrm{O}_{8} \mathrm{I}_{4}$ sub-structure, whereas the secondary unit cell given by the relationship $a_{2}{ }^{*}=a_{1}{ }^{*}+q, b_{2}{ }^{*}=b_{1}{ }^{*}, c_{2}{ }^{*}=c_{1}{ }^{*}$ yielding $a=3.4797 \AA, b=18.508 \AA, c=10.7768 \AA, \beta=97.915^{\circ}, q=$ $(\alpha 0 \gamma), \alpha=0.1852, \gamma=0.3451$ contains $\mathrm{Zn}$ only. This model refines very well yielding $R_{1}$ values better than $6 \%$ for main reflections and better than $12 \%$ and $18 \%$ for first- and secondorder satellites, respectively. The number of $\mathrm{Sb}$ positions in the primary cell is 4 , whereas the number of $\mathrm{Zn}$ positions in the secondary cell is 3 . However, because of the metric relationship between the two unit cells, the relative amount $\mathrm{Sb}: \mathrm{Zn}$ is not $4: 3$, but rather $4: 3.682$; that is, because the $\mathrm{Zn}$ content refers to a smaller cell, it must be multiplied by the ratio of the $a$-axes of the two cells, 4.271/3.4797. This still leaves the structure unbalanced with respect to charge, for which there are several possible remedies. The answer might be found in the partial replacement of $\mathrm{O}$ by $\mathrm{OH}$, the oxidation of $\mathrm{Sb}$ (III) to $\mathrm{Sb}(\mathrm{v})$ or the under-occupancy of either oxygen or iodine. The oxidation of $\mathrm{Sb}$ is unlikely because of the absence of oxidizing agents in the synthesis and the local coordination of $\mathrm{Sb}$ that clearly indicates the trivalent state throughout the structure. Similarly, the absence of iodide should be very

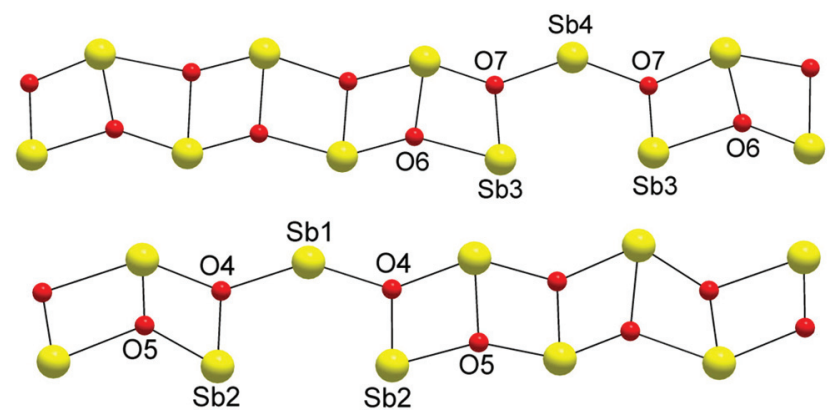

Fig. 6 Two types of Sb-O ladders. Note that oxygen vacancies balance the charge deficiency. In one ladder, there are $\mathrm{O} 6$ vacancies, and in the other, 05 vacancies. noticeable as negative residual electron density. The most likely charge compensation is therefore either partial occupancies on oxygen and/or the presence of hydrogen in the structure. The latter can hardly constitute the sole contribution to charge balance because this would require a rather substantial moisture content in the reaction mixture. Given that the title compounds are the main product of the reaction, the required hydrogen content is $\left[\mathrm{Sb}_{4} \mathrm{O}_{7.38}(\mathrm{OH})_{0.62} \mathrm{I}_{4}\right]\left[\mathrm{Zn}_{3}\right]_{1.23}$, rather more than expected from only contaminant water. This leaves oxygen vacancies as the only plausible main contributor to balance the charge of the non-stoichiometry.

It was found that bond valence sum calculations were quite a useful tool in this quest. While the BVS for all the Sb positions vary, the BVS of Sb1 stands out as singular, reaching a maximum value of well above four. A closer inspection reveals that the high value of this BVS is caused by a short Sb1-O5 distance over part of a range of the internal coordinate, describing the propagation of the structure along the direction of the $\boldsymbol{q}$-vector. Introducing occupational modulation on position $\mathrm{O} 5$ yields an improvement of the fit of the model to the data and reduces the offending BVS value to one more on par with those of the other Sb positions. The reduced occupancy of $\mathrm{O} 5$ also brings the compound closer to an overall charge balance. A somewhat less problematic but still high BVS is found for $\mathrm{Sb} 3$, and herein, the cause is a short distance to O6. Following the procedure for $\mathrm{O} 5$, an occupational modulation was introduced for O6, which led to further improvement and a change in composition to slightly below the ideal value $\left[\mathrm{Sb}_{4} \mathrm{O}_{7.69} \mathrm{X}_{4}\right]$ $\left[\mathrm{Zn}_{3}\right]_{1.23}$. In the final model, the sum of the occupancies for positions $\mathrm{O} 5$ and $\mathrm{O} 6$ was set at 1.69 to avoid overcompensating for $\mathrm{Zn}$ deficiency. Unsurprisingly, the agreement between model and data is quite insensitive to such small changes in oxygen content.

The structure is composed of columns centered by three $\mathrm{Zn}$ positions, with the central being coordinated exclusively by oxygen, whereas the two outer columns also bind to $\mathrm{Cl} / \mathrm{Br} / \mathrm{I}$. 

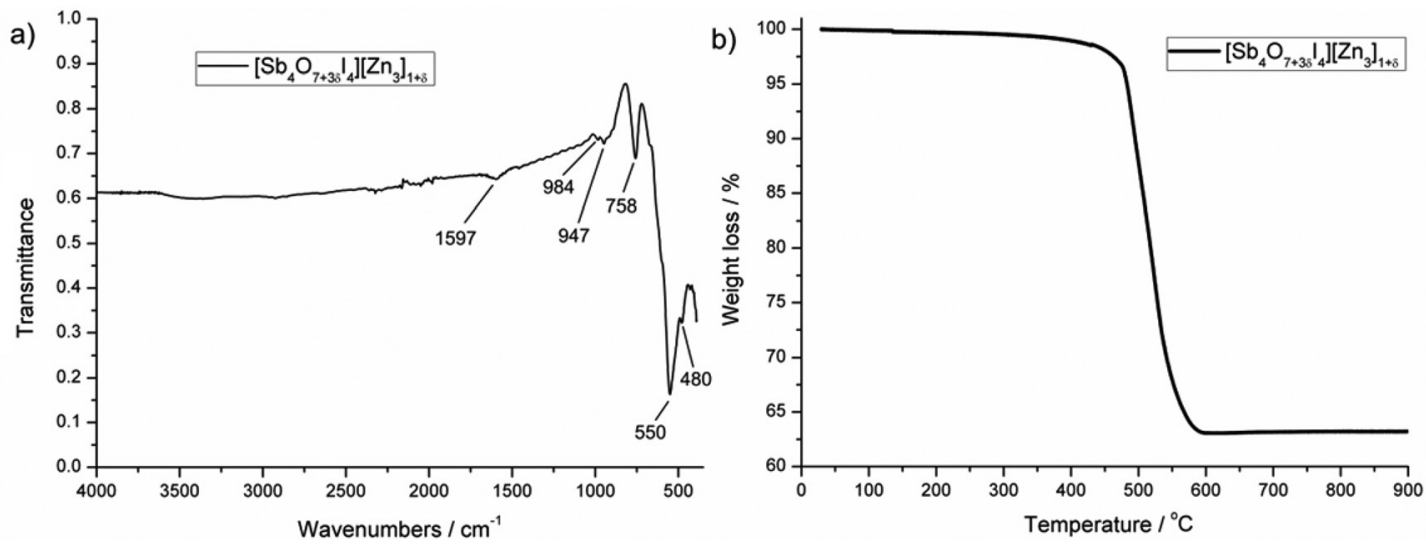

Fig. 7 (a) FT-IR spectrum and (b) TG curve of $\left[\mathrm{Sb}_{4} \mathrm{O}_{7+3 \delta} \mathrm{I}_{4}\right]\left[\mathrm{Zn}_{3}\right]_{1+\delta}$.

The oxygen atoms are further connected to $\mathrm{Sb}$ atoms belonging to $\mathrm{Sb}-\mathrm{O}$ ladders. The structure looks rather simple when viewed along the $a$ direction (see Fig. 3). In a perpendicular view, the complexity becomes more pronounced. The mismatch between $\mathrm{Zn}$ and the rest of the structure is most easily seen if the $\mathrm{Sb}-\mathrm{O}$ ladders are removed from the column (see Fig. 4). The coordination around the three $\mathrm{Zn}$ atoms is clarified with $t$-plots (see Fig. 5) to show how the coordination number varies, depending on the modulation. The composite nature of the structure leads to a charge imbalance that is compensated by oxygen vacancies, which are located in one of the $\mathrm{Sb}-\mathrm{O}$ ladders (see Fig. 6). The $\mathrm{Sb}-\mathrm{O}$ ladders are strongly reminiscent of the ones in $\mathrm{Sb}_{8} \mathrm{O}_{11} \mathrm{X}_{2} \cdot{ }^{5,6}$ The electron density maps show that the atomic modulation functions capture the behavior of each atomic position well (see ESI†).

Almost phase-pure material (see powder diffractogram in ESI $\dagger$ ) could be synthesized for the iodine compound, which was used to collect an IR spectrum and to study thermal decomposition. Fig. 7a shows the transmission IR spectrum for $\left[\mathrm{Sb}_{4} \mathrm{O}_{7+3 \delta} \mathrm{I}_{4}\right]\left[\mathrm{Zn}_{3}\right]_{1+\delta}$ in the range 4000 to $400 \mathrm{~cm}^{-1}$. Intense peaks are observed in the low-energy region, which are most probably due to $\mathrm{Sb}-\mathrm{O}$ and $\mathrm{Zn}-\mathrm{O}$ vibrations. The absence of peaks in the high-energy region confirms the absence of hydroxyl groups, which would give rise to strong signals. Thermogravimetry (TG) data of $\left[\mathrm{Sb}_{4} \mathrm{O}_{7+3 \delta} \mathrm{I}_{4}\right]\left[\mathrm{Zn}_{3}\right]_{1+\delta}$ were recorded from $30-900{ }^{\circ} \mathrm{C}$ in a nitrogen atmosphere with a heating rate of $5{ }^{\circ} \mathrm{C} \mathrm{min}^{-1}$. The TG curve in Fig. $7 \mathrm{~b}$ shows that the compound is stable up to $400{ }^{\circ} \mathrm{C}$ and decomposes shortly thereafter in a single step by releasing iodine as $\mathrm{I}_{2}(\mathrm{~g})$. This is in good agreement with the total weight loss of about $37 \%$. A powder diffraction pattern of the decomposition product shows a mixture of the oxides $\mathrm{ZnSb}_{2} \mathrm{O}_{6}$ and $\mathrm{Zn}_{2.33} \mathrm{Sb}_{0.67} \mathrm{O}_{4}$, which implies that antimony has been oxidized to $\mathrm{Sb}(\mathrm{v})$.

\section{Conclusions}

The new isostructural compounds $\left[\mathrm{Sb}_{4} \mathrm{O}_{7+3 \delta} \mathrm{X}_{4}\right]\left[\mathrm{Zn}_{3}\right]_{1+\delta},(\mathrm{X}=\mathrm{Cl}$, $\mathrm{Br}, \mathrm{I}), \delta \approx 0.2$ were synthesized via chemical reactions in evacu- ated and sealed silica tubes. The crystal structure was found to be incommensurately modulated and was refined in the monoclinic $3+1$ dimensional space group $P 2_{1}(\alpha 0 \gamma) 0$ having a $\boldsymbol{q}$ vector in the $a c$-plane. The close-to-perfect orthorhombic pseudo-symmetry of the fundamental unit cell and the presence of two (orthorhombically) symmetry-equivalent $\boldsymbol{q}$-vectors results in pseudo merohedral twinning. The structure consists of one-dimensional columns having the $\mathrm{Zn}$ atoms in the center to which ladders of antimony oxides are attached. The domination of first-order and second-order satellites for $1 \mathrm{kl}$ and $2 \mathrm{kl}$ reflections, respectively, strongly indicate a composite behavior and that all the $\mathrm{Zn}$ atoms were described in a second composite unit cell. The overall charge balance was obtained by introducing oxygen vacancies in the antimony ladders, which is supported by bond valance sum calculations and by the IR measurements that do not show any signs of hydroxyl groups being present. From TG, one can observe the decomposition of the iodide phase in a single step above $400{ }^{\circ} \mathrm{C}$ by releasing $\mathrm{I}_{2}(\mathrm{~g})$ and oxidising antimony to $\mathrm{Sb}(\mathrm{v})$.

\section{Acknowledgements}

The Swedish Research Council is acknowledged for financial support.

\section{References}

1 Z. Mayerová, M. Johnsson and S. Lidin, J. Solid State Chem., 2005, 178, 3471-3475.

2 Z. Mayerová, M. Johnsson and S. Lidin, Angew. Chem., Int. Ed., 2006, 45, 5602-5606.

3 R. Becker, M. Johnsson, R. K. Kremer and P. Lemmens, Solid State Sci., 2003, 5, 1411-1416.

4 S. Menchetti, C. Sabeli and R. Trosti-Rerroni, Acta Crystallogr., Sect. C: Cryst. Struct. Commun., 1984, 40, 1506-1510.

5 Z. Mayerová, M. Johnsson and S. Lidin, Solid State Sci., 2006, 8, 849-854. 
6 S. Lidin, M. Johnsson and Z. Hugonin, Solid State Sci., 2009, 11, 1198-1205.

7 J. Sun, S. Lee and J. Lin, Chem. - Asian J., 2007, 2, 12041229.

8 B. D. Cutforth, Preparation, Structural Characterization and Electrical Properties of Some Polyatomic Cations of Mercury, Open Access Dissertations and Theses, Paper 3741, McMaster University, Canada, 1975.

9 I. D. Brown, B. D. Cutforth, C. G. Davies, R. J. Gillespie, P. R. Ireland and J. E. Vekris, Can. J. Chem., 2011, 52, 791793.

10 M. Evain, F. Boucher, O. Gourdon, V. Petricek, M. Dusek and P. Bezdicka, Chem. Mater., 1998, 10, 3068-3076.

11 N. A. Jordan, P. D. Battle, S. van Smaalen and M. Wunschel, Chem. Mater., 2003, 15, 4262-4267.
12 M. Zakhour-Nakhl, J. B. Claridge, J. Darriet, F. Weill, H.-C. zur Loye and J. M. Perez-Mato, J. Am. Chem. Soc., 2000, 122, 1618-1623.

13 A. E. Abed, E. Gaudin, H.-C. zur Loye and J. Darriet, Solid State Sci., 2003, 5, 59-71.

14 S. Stahl, Ark. Kemi, Mineral. Geol., 1943, 17, 1-7.

15 L. Palatinus and G. Chapuis, J. Appl. Crystallogr., 2007, 40, 786-790.

16 V. Petříček, M. Dušek and L. Palatinus, JANA-2006, Institute for Physics AVCR, Praha, Czech Republic, 2006.

17 S. van Smaalen, Phys. Rev., 1991, B43, 1133011341.

18 S. van Smaalen, Crystallogr. Rev., 1995, 4, 79-202.

19 K. Brandenburg, DIAMOND, Release 2.1e, Crystal impact GbR, Bonn, Germany, 2000. 